\title{
Spin coating of conjugated polymers for electronic and optoelectronic applications
}

\author{
Chao-Ching Chang ${ }^{\mathrm{a}}$, Chia-Ling Pai ${ }^{\mathrm{a}}$, Wen-Chang Chen ${ }^{\mathrm{a}, *}$, Samson A. Jenekhe ${ }^{\mathrm{b}, *}$ \\ ${ }^{a}$ Department of Chemical Engineering and Institute of Polymer Science and Engineering, National Taiwan University, Taipei, Taiwan 106, R.O.C. \\ ${ }^{\mathrm{b}}$ Department of Chemical Engineering and Department of Chemistry, University of Washington, Seattle, WA 98195-1750, USA
}

Received 29 June 2004; accepted in revised form 3 December 2004

Available online 15 January 2005

\begin{abstract}
Experimental and theoretical study of the spin coating deposition of thin and ultrathin films from dilute solutions of four conjugated polymers, including poly[2-methoxy-5-(2'-ethylhexyloxy)-1,4-phenylenevinylene] (MEH-PPV), regioregular poly(3-hexylthiophene), poly(9,9-dioctylfluorenyl-2,7-yleneethynylene), and poly(2,2'-(3,3'-dioctyl-2,2'-bithienylene)-6,6'-bis(4-phenylquinoline)), is reported. Dilute solutions (0.3-2.0 wt.\%) of the four conjugated polymers in chloroform were found to be Newtonian fluids with viscosities of 0.7-27.9 cp. The measured film thickness $\left(h_{\mathrm{f}}\right)$ of the conjugated polymers was found to be well correlated to the initial solution concentration $\left(x_{1,0}\right)$ and the spin speed $(\omega)$ by the simple expression, $h_{\mathrm{f}}=\mathrm{k} \mathrm{x}_{1,0} \omega^{-\beta}$. The exponent $\beta$ is 0.5 for MEH-PPV but is reduced to 0.4 for the other three conjugated polymers. The difference in the $\beta$ values can be explained by the effect of the accelerative period on the spin coating of less viscous dilute polymer solutions as verified by numerical simulation. A modified Meyerhofer's model was also found to well correlate the film thickness with the fundamental physical properties of the polymers and solvent. These experimental and theoretical results provide a basis for understanding and optimizing the preparation of thin and ultrathin films of conjugated polymers by spin coating.

(C) 2004 Elsevier B.V. All rights reserved.
\end{abstract}

Keywords: Organic semiconductors; Coating; Polymers; Film thickness

\section{Introduction}

Conjugated polymers are of wide interest for applications in electronics and optoelectronics, including light emitting diodes [1-4], thin film transistors [5-7], photovoltaic cells $[8,9]$, and electrochromic cells [10]. Spin coating is the primary process for the deposition of uniform thin and ultrathin films of conjugated polymers for these device applications. Fundamental studies of the morphology and physical properties of conjugated polymers, such as photophysics, charge transport, electrical conductivity, photoconductivity, third-order optical nonlinearity, are also commonly done on spin coated thin $(0.2-1.0 \mu \mathrm{m})$ and ultrathin $(<0.2 \mathrm{~nm})$ films. It has been well documented that

\footnotetext{
* Corresponding authors. Tel.: +886 223628398; fax: +886 223623040 . E-mail addresses: chenwc@ntu.edu.tw (W.-C. Chen), jenekhe@u.washington.edu (S.A. Jenekhe).
}

the film thickness plays a critical role in the morphology and properties of conjugated polymers and the performance of devices based on polymer semiconductors [1-10]. Although there have been many studies of the spin coating process for many other materials [11-31], including photoresists $[12,16,22,23]$, polyimides [13,24,30], sol-gel materials [25] and polyimide-silica hybrid materials [31], neither experimental nor theoretical analysis of the spin coating of conjugated polymer solutions has been reported.

Experimental and theoretical analyses of the spin coating of thick films $(>1 \mu \mathrm{m})$ of photoresists, polyimides, sol-gel materials or polyimide-silica hybrid materials in different solvents have been reported. The dry (final) film thickness, $h_{\mathrm{f}}$, after spin coating of a polymer solution was found to be correlated to the initial polymer weight fraction, $x_{1,0}$, and the spin speed, $\omega$, by Eq.(1) [12,22]:

$$
h_{\mathrm{f}}=k x_{1,0} \omega^{-\beta}
$$




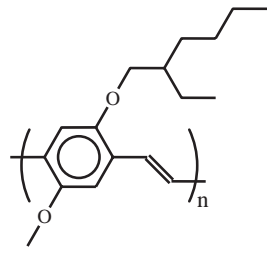

MEH-PPV

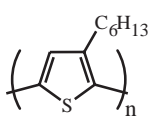

P3HT

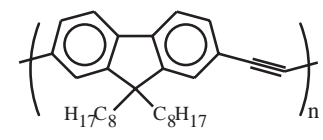

PDOFE

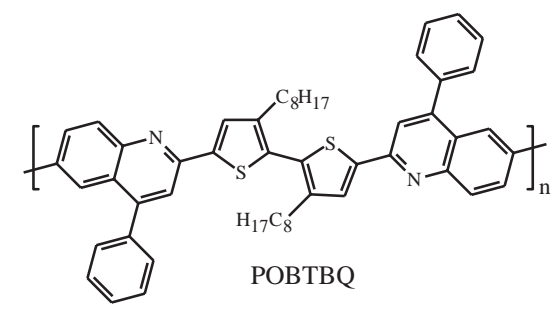

Fig. 1. The molecular structures of the conjugated polymers used in this study.

where $k$ is a constant that depends on the concentration, solution viscosity, and other properties of the polymer and solvent. In the case of most photoresists or spin-on-glass (SOG) materials, the exponent $\beta$ of spin speed is close to $0.5[12,22]$. However, for polyimides or hybrid materials, the exponent $\beta$ shows a wide variation from 0.5 to 1.0 [22]. Such a variation of the exponent $\beta$ has been explained as due to the relative evaporation rate of solvent or achievement of steady state during spin coating [21,22].

Typically, the film thickness of spin coated photoresists or waveguide materials is in the range of several micrometers [12,30,31]. However, spin coated conjugated polymers for electronic or optoelectronic devices typically have a thickness in the sub-micron range. For example, the film thickness of conjugated polymers in light emitting diodes or photovoltaic cells is generally in the range of 50-200 nm $[1-4,8,9]$. For such ultrathin films spin coated from dilute polymer solutions, there are just few prior studies of the spin coating process. Prior studies of the spin coating of ultrathin films of poly(methyl methacrylate) (PMMA) and polystyrene $[27,28]$, however, are not applicable to conjugated polymers. $\pi$-conjugated polymers are largely rigid-rod polymers, whose solution rheological properties can vary from Newtonian to non-Newtonian and isotropic to liquid crystalline [32-34]. Little is currently known about the rheological properties of solutions of even the most widely used conjugated polymers such as poly(alkythiophene)s, derivatives of poly(p-phenylenevinylene), polyfluorenes, and polyquinolines.

In this paper, we present the first experimental and theoretical study of the spin coating process for the deposition of thin and ultrathin films of several conjugated polymers. We investigated the spin coating of dilute solutions of poly[2methoxy-5-(2' -ethylhexyloxy)-1,4-phenylenevinylene] (MEH-PPV), regioregular poly(3-hexylthiophene) (P3HT), poly(9,9-dioctylfluorenyl-2,7-yleneethynylene) (PDOFE), and poly(2,2'-(3,3'-dioctyl-2,2' -bithienylene)-6, 6' -bis(4phenylquinoline)) (POBTPQ). The molecular structures of these polymers are shown in Fig. 1; these conjugated polymers are currently used in light-emitting diodes or thin film transistors $[1,4,35]$. We show that dilute solutions of these conjugated polymers have Newtonian rheological properties. We examined the effects of the polymer solution concentration, solution viscosity, spin speed, and other parameters on the film thickness obtained by spin coating. We show that the expression of Eq. (1) can be used to correlate the film thickness with solution concentration and spin speed. The effect of the spin coating condition and the viscosity of solution on the $\beta$ value was also discussed. A modified Meyerhofer's model was also found to correlate the film thickness of a spin coated conjugated polymer with the fundamental physical properties of the polymer and solvent.

\section{Experimental details}

MEH-PV ( $\overline{\mathrm{M}}_{\mathrm{n}}=86,000$, polydispersity index (PDI, $\overline{\mathrm{M}}_{\mathrm{n}}$ / $\left.\left.\overline{\mathrm{M}}_{\mathrm{n}}\right)=1.52\right)$, MEH-PPV-2 ( $\left.\overline{\mathrm{M}}_{\mathrm{n}}=125,000, \mathrm{PDI}=1.06\right)$, regioregular P3HT (98.5\% head-to-tail, $\overline{\mathrm{M}}_{\mathrm{n}}=27,360$, PDI=3.18), and PDOFE $\left(\overline{\mathrm{M}}_{\mathrm{n}}=5300, \mathrm{PDI}=2.20\right)$ were purchased from Aldrich (Milwaukee, WI, USA) and used without further purification. POBTPQ $\left(\overline{\mathrm{M}}_{\mathrm{n}}=64,900, \mathrm{PDI}=2.76\right)$ was synthesized and characterized according to a previous report [4]. The densities of the conjugated polymers were estimated by the group contribution method [36] and the values are listed in Table 1.

The polymers were dissolved in chloroform to form solutions of different concentrations (weight fractions of polymers). A Brookfield viscometer (DV-II+) and an Ubbelohde viscometer were used to measure the absolute solution viscosity $\left(\eta_{0}\right)$. Each polymer solution was spin coated onto a 2-inch silicon wafer. The spin speeds were $1000,2000,3000,4000$, and $5000 \mathrm{rpm}$, respectively, and the spin time was $60 \mathrm{~s}$. The coated film was then dried on a hot plate at $60{ }^{\circ} \mathrm{C}$ for $10 \mathrm{~min}$ and at $60{ }^{\circ} \mathrm{C}$ in a vacuum furnace for $1 \mathrm{~h}$ to remove the solvent completely. The thickness of the polymer thin films was measured using a surface profilometer (Veeco, Dektak 3030 ST).

Table 1

The solution properties and spin coating parameters of conjugated polymers

\begin{tabular}{lllrrr}
\hline Polymer & $\rho_{1}\left(\mathrm{~g} / \mathrm{cm}^{3}\right)^{\mathrm{a}}$ & $x_{1,0}(\mathrm{wt} . \%)$ & $\eta_{0}(\mathrm{cp})$ & $k\left(\times 10^{-3}\right)$ & $\beta$ \\
\hline MEH-PPV & 0.99 & 0.3 & $2.45^{\mathrm{b}}$ & 521 & 0.47 \\
& & 0.5 & $5.74^{\mathrm{b}}$ & 881 & 0.49 \\
& & 1.0 & $27.86^{\mathrm{b}}$ & 1629 & 0.49 \\
P3HT & \multirow{2}{*}{1.02} & 0.5 & $0.76^{\mathrm{c}}$ & 194 & 0.38 \\
& & 1.0 & $1.07^{\mathrm{c}}$ & 216 & 0.39 \\
& & 2.0 & $1.92^{\mathrm{c}}$ & 264 & 0.39 \\
PDOFE & 0.94 & 1.0 & $0.71^{\mathrm{c}}$ & 188 & 0.37 \\
& & 2.0 & $0.85^{\mathrm{c}}$ & 180 & 0.37 \\
POBTPQ & 1.08 & 1.0 & $1.57^{\mathrm{b}}$ & 319 & 0.43 \\
\hline
\end{tabular}

${ }^{\text {a }}$ Calculated by the group contribution method.

b Measured on a Brookfield viscometer.

c Measured on a Ubbelohde viscometer. 


\section{Results and discussion}

\subsection{Rheological properties of polymer solutions}

Because there is currently no available information on the rheological properties of solutions of MEH-PPV, P3HT, PDOFE, and POBTPQ, we investigated the rheology of these conjugated polymers in chloroform solutions. Representative shear stress versus shear rate data is shown in Fig. 2 for three solution concentrations of MEH-PPV. Linear relationships indicating Newtonian flow behavior are observed in the three MEH-PPV solutions of Fig. 2. This means that the solutions are Newtonian fluids as-prepared. The solutions of the other three conjugated polymers were also found to be Newtonian fluids. The measured absolute viscosities of the conjugated polymer solutions are listed in Table 1 . The viscosity of MEH-PPV solutions is in the range of 2.45-27.86 cp (centipoise) as the solution concentration is increased from 0.3 to $1.0 \mathrm{wt} . \% \mathrm{MEH}-\mathrm{PPV}$. The viscosities of the other conjugated polymer solutions are in the range of $0.71-2.37 \mathrm{cp}$. The polymer solution viscosity, $\eta$, can be expressed as a power-law function of the concentration [12]:

$\eta=\eta_{2}+a x_{1}^{\mathrm{b}}$

where $\eta_{2}$ is the solvent viscosity and $x_{1}$ is the polymer weight fraction. Fig. 3 shows the relationship between the viscosity and the polymer weight fraction of MEH-PPV and P3HT solutions in chloroform. By fitting Eq. (2) to the data, the expressions of $\eta(\mathrm{cp})=0.54+727,300 \mathrm{x}_{1}^{2.22}$ and $\eta$ $(c p)=0.54+255 x_{1}^{1.34}$ were obtained for solutions of MEHPPV and P3HT, respectively. Note that the viscosity of the solvent $\left(\eta_{2}\right)$, chloroform, is $0.54 \mathrm{cp}$.

These results show that the dilute solutions (0.3-2.0 wt.\%) of the four conjugated polymers in chloroform are Newtonian fluids with as-prepared absolute viscosities of 0.7-27.9 cp. Compared to the extremely stiff conjugated rigid-rod and ladder polymers that readily form liquid crystalline solutions [32-34], the viscosities and their concentration dependence as measured by the exponent $b$

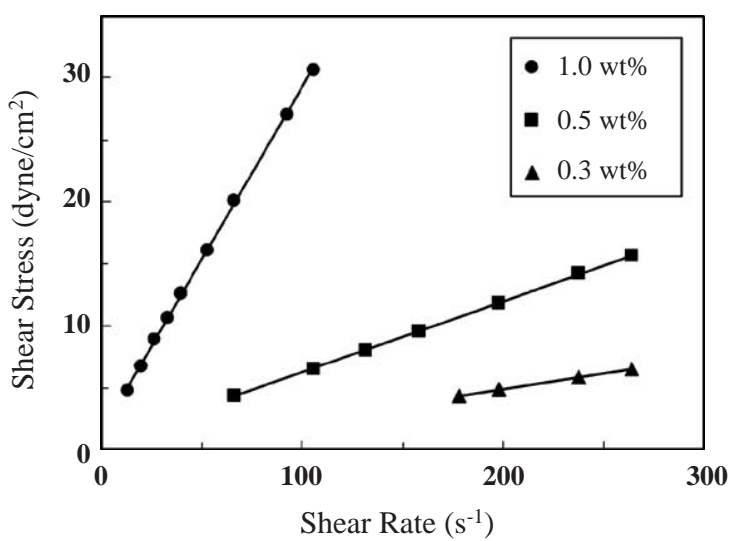

Fig. 2. Variation of the shear stress with the shear rate for MEH-PPV solutions in chloroform.

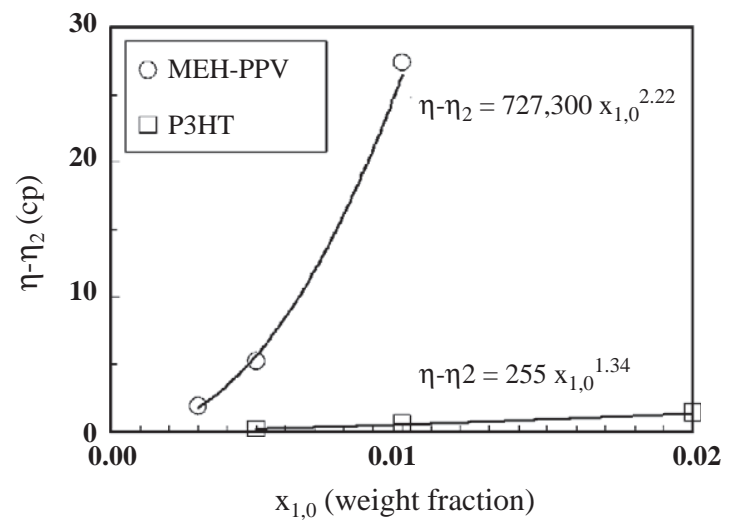

Fig. 3. Viscosity dependence on the concentration of MEH-PPV and P3HT solutions in chloroform.

in Eq. (2) are substantially lower in the present conjugated polymers (MEH-PPV, P3HT, PDOFE, and POBTPQ). We conclude that prior theoretical models of the spin coating of Newtonian polymer solutions, such as Eq. (1), can be a good starting point for describing the spin coating of solutions of these and other conjugated polymers [37].

\subsection{Spin coating of conjugated polymer solutions}

As suggested by Eq. (1), the thickness of a spin coated polymer thin film is proportional to the initial polymer concentration (weight fraction), and the spin speed raised to an exponent $-\beta$. Fig. 4 shows the variation of MEH-PPV film thickness with spin speed and solution concentration. The experimental data are well correlated by the theoretical expression of Eq. (1). The parameter $k$ in Eq. (1) varied from 521,000 to $1,629,000$ as the polymer concentration increased from 0.3 to $1.0 \mathrm{wt} . \%$. However, $\beta$ remained constant at $0.47-0.49$. This suggests that the dependence of film thickness on the spin speed is the same at the different polymer concentrations. The $\beta$ value is close to the theoretical value of 0.5 and to those reported for PMMA and polystyrene [27-29]. For the other conjugated polymer thin films, the film thickness dependence on the spin speed

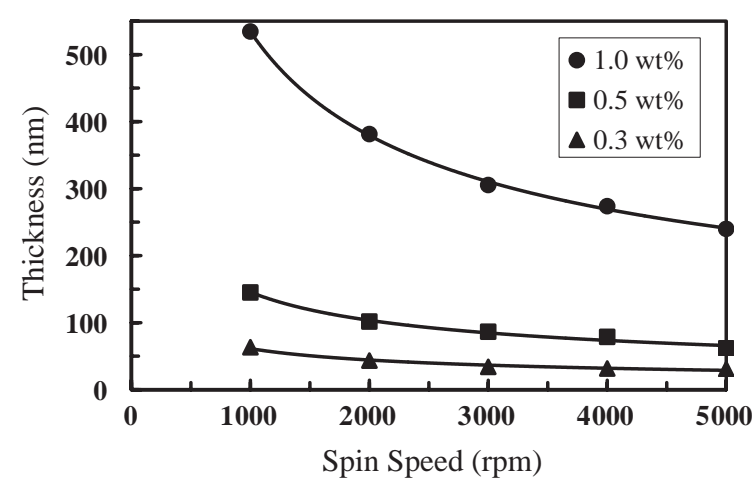

Fig. 4. Variation of the MEH-PPV film thickness with spin speed and polymer concentration. 
could also be satisfactorily fitted by Eq. (1). The spin coating parameters, constant $k$ and exponent $\beta$ of Eq. (1), for all of the conjugated polymer solutions are listed in Table 1. As shown in Table 1 , the value of $\beta$ is around 0.5 for the high viscosity MEH-PPV solutions but is reduced to around 0.4 for the other polymer solutions which have lower viscosities.

The constant $k$ could be correlated to the viscosity $\eta_{0}$ by the expression $k=k^{\prime} \eta_{0}^{\alpha}$. Hence, the effect of solution viscosity on the film thickness was further investigated. Fig. 5 shows the variation of the ratio of the film thickness to initial concentration $\left(h_{\mathrm{f}} / x_{1,0}\right)$ with solution viscosity $\eta_{0}$ and spin speed for MEH-PPV. The film thickness is seen to increase with increasing $\eta_{0}$ and is well-fitted by Eq. (1) if $k=k^{\prime} \eta_{0}^{\alpha}$. Similar results were also found for P3HT. By substituting the various constants into Eq. (1), the film thickness of spin coated MEH-PPV and P3HT can be predicted by Eqs. (3a) and (3b), respectively:

$$
\begin{aligned}
& \text { MEH }- \text { PPV }: h_{\mathrm{f}}(\mathrm{nm})=2.89 \times 10^{6} x_{1,0} \eta_{0}^{0.4} \omega^{-0.5} \\
& \text { P3HT }: h_{\mathrm{f}}(\mathrm{nm})=1.47 \times 10^{6} x_{1,0} \eta_{0}^{0.4} \omega^{-0.4}
\end{aligned}
$$

The average deviation between the experimental data and the theoretical prediction from Eqs. (3a) and (3b) was only 2-3\%. Hence, we conclude that Eqs. (3a) and (3b) can be used to accurately predict the film thickness of MEH-PPV and P3HT spin coated from solutions of known concentration $\left(x_{1,0}\right)$ and viscosity $\left(\eta_{\mathrm{o}}\right)$.

The effect of molecular weight on the derived spincoating model was studied by investigating two different MEH-PPV $\left(\overline{\mathrm{M}}_{\mathrm{n}}=86,000\right)$ and MEH-PPV-2 $\left(\overline{\mathrm{M}}_{\mathrm{n}}=125,000\right)$ at the same solution concentration of $0.3 \mathrm{wt} . \%$ in $\mathrm{CHCl}_{3}$. The values of $k$ and $\beta$ of the MEH-PPV-2 solution fitted by Eq. (1) are $1140 \times 10^{-3}$, and 0.47 , respectively. The $\eta_{\mathrm{o}}$ of the 0.3 wt. $\%$ MEH-PPV-2 is $23.06 \mathrm{cp}$, which is higher than that of the 0.3 wt.\% MEH-PPV solution with $2.45 \mathrm{cp}$. The same $\beta$ for MEH-PPV and MEH-PPV-2 suggests that the dependence of film thickness with spin speed is the same for two different molecular weights of polymer. The difference of $k$ for MEH-PPV and MEH-PPV-2 comes from the different solution viscosity. If we fit the film thickness of the MEH-PPV-2 by Eq.(3a), there is only $6 \%$ difference

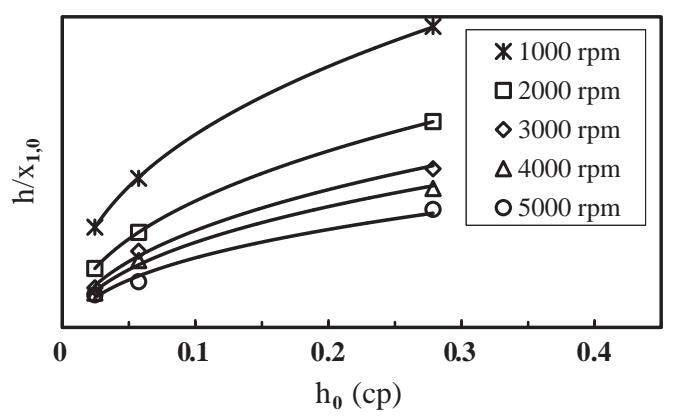

Fig. 5. Variation of the ratio of the film thickness to the initial concentration $\left(h_{\mathrm{f}} / x_{1,0}\right)$ with the solution viscosity and spin speed for MEH-PPV. between the theoretical and experimental results. This indicates that Eq.(3a) could be a general equation for predicting the MEH-PPV thin film for electronic and optoelectronic applications.

The finding that the value of $\beta$ is less than 0.5 for the cases of P3HT, PDOFE, and POBTPQ, as shown in Table 1 requires an explanation. This may be due to the effect of the accelerative period during the early stage of a spin coating process involving very dilute and less viscous solutions $[12,20,25]$. To understand the deviation of $\beta$ from the theoretically expected value of 0.5 , we used a numerical method to calculate the variation of the film thickness with spin time. For a Newtonian fluid, an expression for the rate of convective thinning of a uniform film on a spinning disk has been reported [11]:

$\frac{\mathrm{d} h}{\mathrm{~d} t}=-\frac{2 \rho \omega^{2} h^{3}}{3 \eta}$

where $h, \rho$, and $\eta$ are the film thickness, the initial solution density, and the solution viscosity, respectively. As shown previously the solution film thickness $h$ consists of the thickness of solid polymer $(S)$ and the thickness of solvent $(L)$, and thus, the rate of solution thinning due to convective flow and evaporation can be decomposed into Eq.(5a) and (5b) [12]:

$$
\begin{aligned}
& \frac{\mathrm{d} S}{\mathrm{~d} t}=-\frac{S}{S+L} \frac{2 \rho \omega^{2}(S+L)^{3}}{3 \eta} \\
& \frac{\mathrm{d} L}{\mathrm{~d} t}=-\frac{L}{S+L} \frac{2 \rho \omega^{2}(S+L)^{3}}{3 \eta}-\Lambda
\end{aligned}
$$

where $\Lambda$ is the solvent evaporation term described by Eq.(5c) [20]:

$\Lambda=\left(\frac{c D_{\mathrm{g}}}{v_{\mathrm{g}}^{1 / 2} \rho}\right)\left(\frac{P_{2}^{0} M_{2}}{R T}\right) \omega^{1 / 2}\left(x_{2}-x_{2 \infty}\right)$

where $x_{2}, x_{2 \infty}, c, D_{\mathrm{g}}, v_{\mathrm{g}}, P_{2}^{0}, T, M_{2}$, and $R$ are, respectively, the solvent mass fraction, the solvent mass fraction in the solution that would be in equilibrium with the solvent mass fraction in the gas phase, a constant that depends on the Schmidt number of the overhead gas, the binary diffusivity of the solvent in the overhead gas, the kinematic viscosity of the overhead gas, the solvent vapor pressure, the coating temperature, the solvent molecular weight, and the ideal gas constant. These parameters used in this paper are given in Tables 1 and 2. For a given initial film thickness, Eqs. (5a) (5b) (5c) can be solved numerically. Fig. 6 shows the experimental final film thickness as a function of the spin speed for $1.0 \mathrm{wt} . \%$ MEH-PPV and P3HT solutions. Also shown in Fig. 6 are the numerical solution results. The theoretical results are in a satisfactory agreement with the experimental results, suggesting that the numerical method is accurate. Fig. 7 shows the thickness versus spin time results for $1.0 \mathrm{wt} \% \mathrm{MEH}-$ 
Table 2

Parameters of air and solvent $\left(\mathrm{CHCl}_{3}\right)$ for predicting thin film thickness at $T=298 \mathrm{~K}^{\mathrm{a}}$

\begin{tabular}{ll}
\hline$R=82.06 \mathrm{~atm} \mathrm{~cm} / \mathrm{mol} \mathrm{K}$ & $M_{2}=119.38$ \\
$c=0.5474^{\mathrm{b}}$ & $\rho_{2}=1.50 \mathrm{~g} / \mathrm{cm}^{3}$ \\
$\mathrm{v}_{\mathrm{g}}=0.1553 \mathrm{~cm}^{2} / \mathrm{s}$ & $\eta_{2}=0.54 \mathrm{cp}$ \\
$D_{\mathrm{g}}=0.106 \mathrm{~cm}^{2} / \mathrm{s}$ & $P_{2}^{0}=0.26 \mathrm{~atm}$ \\
& $x_{2, \infty}=0$ \\
\hline
\end{tabular}

${ }^{a}$ Reference [38].

b Reference [20].

PPV and P3HT solutions, respectively, obtained by numerical simulations. As seen in Fig. 7, the conjugated polymer films reach their final thicknesses within a very short time because of the high convection and evaporation rates when the solution viscosity is low and the solvent evaporation (chloroform) is high. For spin coated thick films from highly viscous photoresists $[12,16]$ or polyimide precursor solutions [30], these usually require a spin time of 30-60 s. Besides, the P3HT solution reaches its final thickness much faster than the MEH-PPV solution at the same concentration. This is due to the lower viscosity of the P3HT solution than that of MEH-PPV.

As noted above, the deviation of exponent $\beta$ from 0.5 for three of the conjugated polymers (P3HT, PDOFE, POBTPQ) may be due to the accelerative period at the beginning of spin coating. We now further examine this hypothesis. In the accelerative period, the spin speed is increased from zero to a desired constant speed $\left(\omega_{\text {set }}\right.$, set speed). An exponential equation $\omega=\omega_{\text {set }}\left(1-e^{-10 t}\right)$ was assumed to account for the accelerative period of the spin speed and substituted into Eqs. (5a) and (5b). By testing an example of $\omega_{\text {set }}=1000 \mathrm{rpm}$, the exponent $\beta$ obtained by numerical simulation using $\omega=\omega_{\text {set }}\left(1-e^{-10 t}\right)$ was 0.42 for the 1.0 wt.\% P3HT solution, which is very close to the experimental 0.39 (Table 1). However, if a constant spin speed $\omega=\omega_{\text {set }}(=1000 \mathrm{rpm})$ was employed in the simulation, the $\beta$ value obtained was 0.5 , which is the theoretically predicted value and what we also observed for MEH-PPV. These simulation results confirm our hypothesis that the

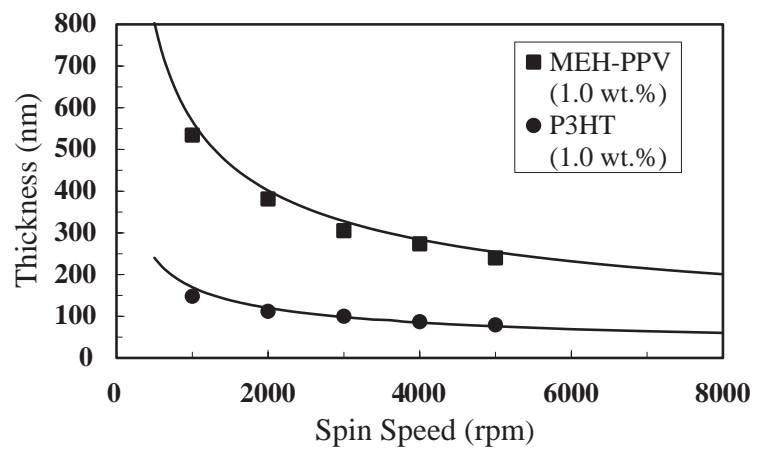

Fig. 6. The predicted final film thickness of the 1.0 wt.\% MEH-PPV and P3HT solutions with spin speed and their comparison with the experimental data. Solid symbols: measured data; solid lines: calculated from numerical method.

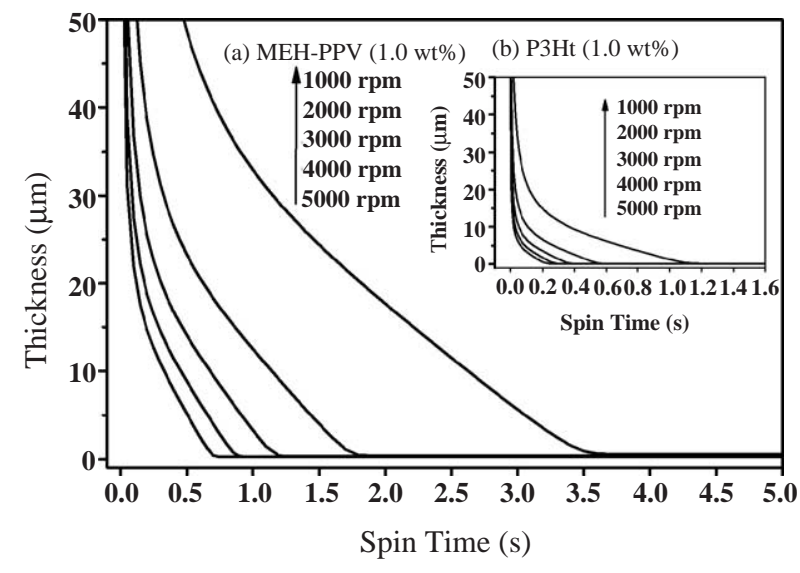

Fig. 7. Numerical simulation of the variation of film thickness with spin time for the (a) $1.0 \mathrm{wt} \% \mathrm{MEH}-\mathrm{PPV}$ solution. Insert figure is the variation of film thickness with spin time for the (b) $1.0 \mathrm{wt} \%$ P3HT solution.

accelerative period significantly affects the film thickness and reduces the exponent $\beta$ for some of the conjugated polymer solutions. Because the time of arriving at the final thickness is mainly inversely proportional to the solution concentration, viscosity, and spin speed, the effect of accelerative time becomes apparent in a very dilute and less viscous solution or at high spin speeds, such as the cases of P3HT, PDOFE, and POBTPQ solutions. Clearly because the MEH-PPV solutions have a higher viscosity than the other conjugated polymers in the present study, the effect of the accelerative period on the film thickness or the exponent $\beta$ is not significant.

The fact that the exponent $\beta$ of Eq. (1) deviated from the theoretically expected 0.5 in the case of solutions of P3HT, PDOFE, and POBTPQ due to their low viscosities means that one can expect higher molecular weight samples of these polymers to result in higher viscosities and thus a $\beta$ value of 0.5 . There is clearly a need to further explore the spin coating of higher molecular weight samples of these conjugated polymers. We suggest that a $\beta$ value of 0.5 be used for these and other conjugated polymers if their solution viscosities are comparable to those of MEH-PPV (Table 1).

Although Eq. (1) has been shown above as an excellent expression for estimating the film thickness of spin coated conjugated polymers, it does not correlate the film thickness with the fundamental physical properties of the polymer and solvent. Bornside et al. [20]. and Hall et al. [27], attempted to calculate the film thickness of spin coated PMMA and polystyrene thin films based on Meyerhofer's model [12] by taking solvent evaporation into account [20]. However, their predicted results were not in good agreement with the experimental data for some polymer/solvent systems. We believe that this was because they did not consider the difference between the polymer solution density and the solvent density. Here, a modified model based on the equations of Meyerhofer [12] and Bornside [20] is used to predict the film thickness of spin coated conjugated 


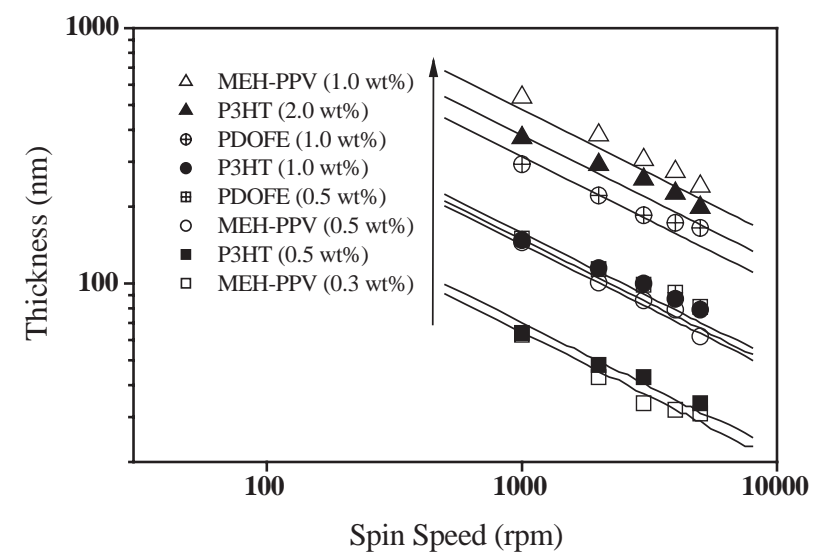

Fig. 8. Variation of the film thickness of MEH-PPV, P3HT and PDOFE with spin speed and polymer concentration. Symbols: experimental data; solid lines: calculated from Eq. (6b).

polymers. The wet film thickness, $h_{\mathrm{w}}$, after spin coating but before drying can be expressed as [26]:

$h_{\mathrm{w}}=\left[\left(\frac{3 \eta_{0}}{2 \rho_{0} \omega^{2}}\right)\left(\frac{c D_{\mathrm{g}}}{v_{\mathrm{g}}^{1 / 2} \rho_{0}}\right)\left(\frac{P_{2}^{0} M_{2}}{R T}\right) \omega^{1 / 2}\left(x_{2,0}-x_{2 \infty}\right)\right]^{1 / 3}$

where $x_{2,0}$ is the initial solvent mass fraction. The final film thickness, $h_{\mathrm{f}}$, taken to be the dry thickness of the conjugated polymer film can be expressed by the following equation:

$h_{\mathrm{f}}=v_{1,0}\left[\left(\frac{3 \eta_{0}}{2 \rho_{0} \omega^{2}}\right)\left(\frac{c D_{\mathrm{g}}}{v_{\mathrm{g}}^{1 / 2} \rho_{0}}\right)\left(\frac{P_{2}^{0} M_{2}}{R T}\right) \omega^{1 / 2}\left(x_{2,0}-x_{2 \infty}\right)\right]^{1 / 3}$

where $v_{1,0}$ is the initial polymer volume fraction in the solution. The definitions of other parameters have previously been explained in Eq. (5c). The predicted film thicknesses of spin coated MEH-PPV, P3HT and PDOFE, using Eq. (6b), and their comparison with experimental data are shown in Fig. 8, respectively. The predicted film thickness shows a very good agreement with the experimental film thickness, especially at low polymer concentrations. However, the predicted film thickness is slightly higher than the experimental data at the higher spin speeds. This is due to the accelerative period in the spin coating process, as discussed above. Therefore, Eqs. (6a) (6b) can be used to predict the film thickness of spin coated conjugated polymers if the physical properties of the polymer and solvent are known.

\section{Conclusions}

Our experimental results for several representative conjugated polymers, including MEH-PPV, P3HT, PDOFE, and POBTPQ, show that their dilute solutions ( $<3 \mathrm{wt} . \%)$ in chloroform have Newtonian rheological properties with viscosity in the $0.7-27.9 \mathrm{cp}$ range. Theoretical models for the spin coating of Newtonian polymer solutions were thus found to be suitable starting points for the analysis of thin and ultrathin films of spin coated conjugated polymers. The measured film thickness of the four conjugated polymers was described well by the simple expression $h_{\mathrm{f}}=k x_{1,0} \omega^{-\beta}$ of Eq. (1), where $\beta$ was 0.5 for MEH-PPV and 0.4 for P3HT, PDOFE, and POBTPQ. Since the deviation of the exponent $\beta$ from the theoretical value of 0.5 is due to the less viscous nature of solutions of the latter three polymers, we expect that higher molecular weight samples of the polymers will show the theoretically expected $\beta$ value. Eq. (6b) was found to correlate the film thickness of the spin coated conjugated polymers with the fundamental physical properties of the polymer and solvent. The present results provide simple methodologies for controlling the spin coating of thin and ultrathin films of conjugated polymers.

\section{Acknowledgement}

Financial support came from the National Science Council, the Ministry of Education, and the Ministry of Economic Affairs of Taiwan, R.O.C. Work at University of Washington was supported by the Air Force Office of Scientific Research (Grant F49620-03-1-0162).

\section{References}

[1] A. Kraft, A.G. Grimsdale, A.B. Holmes, Angew. Chem., Int. Ed. 37 (1998) 402.

[2] S.A. Jenekhe, J.A. Osaheni, Science 265 (1994) 765.

[3] X. Zhang, S.A. Jenekhe, Macromolecules 33 (2000) 2069.

[4] C.J. Tonzola, M.M. Alam, S.A. Jenekhe, Adv. Mater. 14 (2002) 1086.

[5] Z. Bao, A. Dodabalapur, A.J. Lovinger, Appl. Phys. Lett. 69 (1996) 4108.

[6] H. Sirringhaus, N. Tessler, R.H. Friend, Science 280 (1998) 1741.

[7] A. Babel, S.A. Jenekhe, J. Am. Chem. Soc. 125 (2003) 13656.

[8] G. Yu, J. Gao, J.C. Hummelen, F. Wudl, A.J. Heeger, Science 270 (1995) 1789.

[9] S.A. Jenekhe, S. Yi, Appl. Phys. Lett. 77 (2000) 2635.

[10] F. Fungo, S.A. Jenekhe, A.J. Bard, Chem. Mater. 15 (2003) 1264.

[11] A.G. Emslie, F.T. Bonner, L.G. Peck, J. Appl. Phys. 29 (1958) 858.

[12] D.J. Meyerhofer, Appl. Phys. 49 (1978) 3993.

[13] S.A. Jenekhe, Polym. Eng. Sci. 23 (1983) 830.

[14] S.A. Jenekhe, Ind. Eng. Chem. Fundam. 23 (1984) 425

[15] S.A. Jenekhe, Ind. Eng. Chem. Fundam. 23 (1984) 432.

[16] W.W. Flack, D.S. Soong, A.T. Bell, D.W. Hess, J. Appl. Phys. 56 (1984) 1199.

[17] S.J. Shimoji, Appl. Phys. 66 (1989) 2712.

[18] D.E. Bornside, C.W. Macosko, L.E. Scriven, J. Appl. Phys. 66 (1989) 5185 .

[19] D.E. Bornside, R.A. Brown, J. Appl. Phys. 73 (1993) 585.

[20] D.E. Bornside, C.W. Macosko, L.E. Scriven, J. Electrochem. Soc. 138 (1991) 317.

[21] K.J. Skrobis, D.D. Denton, A.V. Skrobis, Polym. Eng. Sci. 30 (1990) 193.

[22] P.C. Sukanek, J. Electrochem. Soc. 138 (1991) 1712.

[23] P.C. Sukanek, J. Electrochem. Soc. 144 (1997) 3959. 
[24] M.D. Bullwinkel, J. Gu, G.A. Campbell, P.C. Sukanek, J. Electrochem. Soc. 142 (1995) 2389.

[25] T.J. Rehg, B.G. Higgins, AIChE J. 38 (1992) 489.

[26] R.K. Yonkoski, D.S. Soane, J. Appl. Phys. 72 (1992) 725.

[27] D.B. Hall, P. Underhill, J.M. Torkelson, Polym. Eng. Sci. 38 (1998) 2039.

[28] C.B. Walsh, E.I. Franses, Thin Solid Films 347 (1999) 167.

[29] C.B. Walsh, E.I. Franses, Thin Solid Films 429 (2003) 71.

[30] Y. Chang, W.C. Wu, W.C. Chen, J. Electrochem. Soc. 148 (2001) F77.

[31] C.C. Chang, K.H. Wei, W.C. Chen, J. Electrochem. Soc. 150 (2003) F147.
[32] S.A. Jenekhe, P.O. Johnson, A.K. Agrawal, Macromolecules 22 (1989) 3216.

[33] S.A. Jenekhe, P.O. Johnson, Macromolecules 23 (1990) 4419.

[34] S.A. Jenekhe, A.K. Agrawal, Chem. Mater. 4 (1992) 95.

[35] N.G. Pschirer, U.H.F. Bunz, Macromolecules 33 (2000) 3961.

[36] D.W. van Krevelen, Properties of polymers, 3rd ed., Elsevier, Amsterdam, 1997.

[37] W.C. Chen, C.L. Liu, C.T. Yen, F.C. Tsai, C.J. Tonzola, N. Olson, S.A. Jenekhe, Macromolecules 37 (2004) 5959.

[38] R.H. Perry, D.W. Green, J.O. Maloney, Perry's handbook of chemical engineering, 6th ed., McGraw-Hill, New York, 1984. 